\title{
Aporte del «De vita Moysis» de Gregorio de Nisa a la inculturación de la teología hoy*
}

Orlando Solano Pinzón**

Para citar este artículo: Solano Pinzón, Orlando. «Aporte del "De vita Moysis" de Gregorio de Nisa a la inculturación de la teología hoy». Franciscanum 163, Vol. LVII (2015): 325-360.

\section{Resumen}

El presente escrito busca contribuir a la elaboración de un marco conceptual que favorezca la inculturación de la teología hoy, a partir del trabajo de inculturación de la teología realizado por Gregorio de Nisa en su obra «De Vita Moysis»; para ello, además de una breve aclaración conceptual, se realiza un ejercicio de interpretación sin ninguna pretensión totalizante, sino como un aporte que promueva la inculturación de la teología hoy.

\section{Palabras clave}

Patrística, Gregorio de Nisa, inculturación, teología, De Vita Moysis.

* El presente escrito corresponde a un fragmento de la investigación realizada para optar por el título de Doctor en Teología, de la Pontificia Universidad Javeriana.

** Licenciado en Filosofía de la Universidad Santo Tomás, sede Bogotá, profesional, licenciado, Magíster y Doctor en Teología de la Pontificia Universidad Javeriana, sede Bogotá. Docente de tiempo completo de la Facultad de Teología de la Pontificia Universidad Javeriana. Miembro del Grupo de Investigación Academia. Contacto: o.solano@javeriana.edu.co. 


\title{
Contribution of the "De vita Moysis" of Gregory of Nyssa for the inculturation of the theology today
}

\begin{abstract}
This paper seeks to contribute to the development of a conceptual framework which will allow the inculturation of theology today, based on the work of inculturation of theology made by Gregory of Nyssa in his work 'De Vita Moysis'. For this reason, in addition to a brief conceptual clarification, there is a non-conclusive exercise of interpretation, but a contribution to promote the inculturation of theology today.
\end{abstract}

\section{Keywords}

Patristic, Gregory of Nyssa, inculturation, theology, De Vita Moysis.

\section{Introducción}

El presente artículo busca señalar el aporte de Gregorio de Nisa a la elaboración de un marco conceptual que sustente la inculturación de la teología hoy. Para tal efecto, en un primer momento se abordará una breve aclaración conceptual, en un segundo momento se presentará el aporte del obispo de Nisa a la elaboración de un marco conceptual que sustente la inculturación y, posteriormente se cerrará con una conclusión.

\section{Noción de inculturación de la teología}

Antes de abordar el concepto «inculturación de la teología» conviene hacer una referencia a los términos cultura y teología, pues existe una amplia variedad de significados. En cuanto al concepto cultura, el presente trabajo comparte la diferenciación que 
establece Lonergan entre la concepción clásica (concebida de forma normativa y, por tanto, no hay sino una cultura) y la concepción empírica (que reconoce la existencia de muchas culturas) ${ }^{1}$. Sobre este primer acercamiento conviene afirmar que la investigación asume la comprensión empírica de cultura, esto es, se reconoce la diversidad cultural, pues se ajusta a la realidad que es propia de la naturaleza humana ${ }^{2}$.

En lo que respecta a la definición de cultura, se asume la planteada por Marcelo de Carvalho Azevedo en su libro Comunidades eclesiais de base e inculturação da fé, compartida por Mario De Franca en su libro La inculturación de la fe. Un abordaje teológico, pues permite relacionarla con la comprensión empírica de cultura a la que antes se ha hecho referencia. Para estos autores

Cultura es el conjunto de sentidos y significados, de valores y patrones, incorporados y subyacentes a los fenómenos perceptibles de la vida de un grupo social concreto, conjunto que, consciente o inconscientemente, es vivido y asumido por el grupo como expresión propia de su realidad humana y pasa de generación en generación, conservando así como fue recibido o transformado efectiva o pretendidamente por el mismo grupo ${ }^{3}$.

La definición anterior permite entender que si bien el hombre crea cultura, esta a su vez le permite realizarse como un ser verdaderamente humano ${ }^{4}$. Además, es posible inferir que la cultura existe a través de las culturas. De allí el carácter de unidad y diversidad que Edgar Morín atribuye a la cultura en el sentido de que «La cultura mantiene la identidad humana en lo que tiene de específico; las culturas mantienen las identidades sociales en lo que ellas tienen de específico» ${ }^{5}$.

1 B. Lonergan, Método en Teología, (Salamanca: Sígueme, 2006), 9.

2 E. Morín, Los siete saberes para la educación del futuro (Bogotá: Ediciones del Ministerio de Educación Nacional, 1996), 22-28.

3 M. Azevedo, Comunidades eclesiais de base e inculturação da fé (São Paulo: Loyola, 1986), 336. Mario De França en su libro La inculturación de la fe: Un abordaje teológico, (Bogotá: CELAM, 2004), 70. $\mathrm{Al}$ respecto, el Concilio Vaticano II en la Gaudium et Spes es claro al afirmar que «Es propio de la persona humana el no llegar a un nivel verdadera y plenamente humano si no es mediante la cultura, es decir, cultivando los bienes y los valores naturales. Siempre, pues, que se trata de la vida humana, naturaleza y cultura se hallen unidas estrechísimamente». Concilio Vaticano II, «Constitución Gaudium et Spes», en Constituciones, decretos, declaraciones (Madrid: BAC, 1966), n 53. 
A partir del acercamiento realizado a la noción de cultura, pasamos ahora a comentar el término «inculturación», aclarando que aunque dicha categoría es un neologismo que entró a formar parte del lenguaje oficial eclesiástico en la segunda mitad del siglo XX, la problemática que está en la base de la misma, ha estado presente a lo largo de toda la historia de la Iglesia ${ }^{6}$. En este sentido, según Poupard ${ }^{7}$ el concilio de Jerusalén narrado en Hechos de los Apóstoles es prueba de la siempre presente necesidad de inculturar la fe y la teología.

Concretamente, desde el año 1978 con ocasión de un sínodo sobre catequesis $^{8}$ abordó el tema el P. Arrupe, quien comentó las razones de la «inculturación» asumiéndola en clave de encarnación. En este caso, para el P. Arrupe:

La inculturación es la encarnación de la vida y del mensaje cristianos en un espacio cultural concreto, de suerte que no solo esta experiencia se exprese con los elementos propios de la cultura en cuestión, sino que esta misma experiencia se transforme en un principio de inspiración, norma y fuerza de unificación a la vez, que transforme y recree esta cultura, para situarnos en el origen de una nueva creación ${ }^{9}$.

Este énfasis referido a la encarnación fue retomado por Nicolás Standaert en un artículo intitulado L 'histoire d'un néologisme, en el cual describe dos maneras de comprender el término «inculturación» en los documentos eclesiales: como adaptación y como encarnación. Particularmente Standaert deja al descubierto la insuficiencia de la adaptación, pues se limita a una función de traducción, y considera oportuno apropiar la inculturación como encarnación ya que al tener como referente el misterio de la encarnación, como dinamismo remite a la inserción, enraizamiento, integración y apropiación, sin

Cf. P. Poupard, «Los Padres de la Iglesia: actualidad de una inculturación de la fe», en AA.VV. El diálogo fe-cultura en la antigüedad cristiana (Pamplona: EUNATE, 1996), 28-29.

Sobre esta dinámica de inculturación, el mismo Poupard afirma que «Aun cuando el término inculturación, entró a formar parte del lenguaje oficial eclesiástico hace muy poco tiempo, la problemática de la inculturación está presente a lo largo de toda la historia de la Iglesia». Ibíd., 29.

Cf. J.L. Moreno Martínez, La luz de los Padres: Temas patrísticos de actualidad eclesial (Toledo: Instituto Teológico San Ildefonso, 2005), 143-144.

Citado por B. Laurent, Iniciación a la práctica de la teología: La práctica, acciones pastorales (Madrid: Cristiandad, 1983), 239. 
excluir las posibles limitantes que pueden surgir del diálogo con las culturas y la referencia al lenguaje.

Además, el aporte fundamental y punto de partida de la inculturación entendida en términos de encarnación remite a reconocer que no conocemos todavía a Cristo en su plenitud, y que es gracias a la manera como una cultura experimenta y realiza los desafíos del Evangelio, que otras culturas ya cristianas pueden convertirse y renacer a una imagen cada vez más pura de Cristo ${ }^{10}$. En relación con lo anterior es posible afirmar con Rovira Belloso que «el criterio de la Encarnación (que incluye la creación) puede tomarse no como un criterio entre muchos, sino como el criterio rector de todo el proceso de inculturación ${ }^{11}$.

Dentro de este ejercicio de aclaración de términos, pasamos ahora a describir la comprensión del concepto teología que se maneja en la presente investigación. Debido a la multiplicidad de definiciones que se han proferido sobre el término en cuestión ${ }^{12}$ y dada la necesidad de concretar nuestra comprensión al respecto, concebimos la teología más que por la semántica del término, por las características que ha asumido a lo largo de los siglos, por ello, al hablar de teología hacemos referencia a la función mediadora entre una determinada matriz cultural y el significado y valor de la religión en dicha matriz ${ }^{13}$, al marcado acento histórico sobre el cual se elabora y el dato de fe que le confiere su especificidad en términos de reflexión crítica de la praxis histórica a la luz de la $\mathrm{fe}^{14} \mathrm{y}$ al carácter existencial, ético, espiritual, reflexivo, crítico, lingüístico, doctrinal y celebrativo que involucra el encuentro con Dios que envuelve la totalidad de la existencia, el sentimiento, el corazón, la inteligencia y la voluntad ${ }^{15}$.

10 N. Standaert, "L'histoire d'un néologisme. Le terme 'inculturation' dans les documents romains», Nouvelle reveu théologique 110 (1988): 555-570.

11 J. M. Rovira Belloso, Introducción a la teología (Madrid: BAC, 1996), 326.

12 Sobre esta afirmación da razón el libro de J.B. Libanio y A. Murad, intitulado Introducción a la teología. Perfiles, enfoques, tareas (Sao Paulo: Ediciones Loyola, 1996), en el cual se enuncian 19 definiciones de teólogos reconocidos.

13 Cf. B. Lonergan, op. cit., 9.

14 Cf. G. Gutiérrez, Teología de la liberación (Salamanca: Sígueme, 1972), 34.

15 Cf. J.B. Libanio, y A. Murad, op. cit., 106. 
A partir de las características antes descritas, podemos entender la inculturación de la teología en clave de encarnación, como el proceso de apropiación de una matriz cultural, para repensar, decir, vivir y celebrar desde ella, la manera como se desoculta Dios en los acontecimientos de la historia que viven las mujeres y los hombres que comparten dicha matriz ${ }^{16}$. Si bien, el lenguaje a través del cual se recibe y expresa el desocultarse de Dios siempre se queda corto, pueden, de manera analógica, hacerse acercamientos provisorios, debido a que el lenguaje humano está abierto a hacer presente y comunicar una realidad que lo trasciende.

\section{Marco conceptual de la inculturación de la teología desde el aporte de Gregorio de Nisa en su obra «De Vita Moysis ${ }^{17}$.}

El ejercicio que viene a continuación se presenta como un esfuerzo de interpretación, entre los muchos que pueden darse, que no tiene pretensiones de haber agotado el tema, pero sí de haber retomado un camino de reencuentro con la tradición de los Padres de la Iglesia, para aprender de ellos el talante que exige el ejercicio impostergable de inculturación de la teología entendido en clave de encarnación.

Dentro de los aportes se establecerá la diferencia entre fuentes y características de la inculturación de la teología, con el ánimo de explicitar los elementos que permanecen siempre y le imprimen carácter al ejercicio teológico, de aquellos que le dan cuerpo, evocando la obra del Niseno para que el lector pueda validar la coherencia de la interpretación realizada.

16 La apropiación de la matriz cultural es esencial en el proceso de inculturación debido a que, como señala Robira Belloso, «una cultura solo puede ser fecundada desde dentro, desde su libertad, no desde fuera y desde el dominio exterior ejercido con medios puramente humanos». J. M. Rovira Belloso, op. cit., 327. La negrilla busca evidenciar la referencia que hace Rovira a la constitución pastoral Gaudium et Spes, n.42.

17 Esta obra de Gregorio de Nisa evidencia la madurez intelectual y espiritual del autor y busca responder a la pregunta ¿Cuál es la perfección en la virtud? 
Con el ánimo de entrar en la lógica del espíritu del obispo de Nisa, compartimos la expresión que usa en el momento de la interpretación de la descripción del tabernáculo celeste, aplicada en este caso al ejercicio que vamos a realizar: «Por nuestra parte, proponemos hipotéticamente nuestra interpretación de este asunto, y la sometemos al buen sentido de quienes la oigan, dejando su aceptación o su rechazo al parecer de quien la examine» ${ }^{18}$.

\subsection{Fuentes}

\subsubsection{La Escritura como paideia cristiana}

Dentro del ejercicio de inculturación de la teología que realizó el obispo de Nisa, la Escritura, a la cual reconoce como inspirada por el Espíritu, constituye la fuente primordial que da sentido al discurso teológico ${ }^{19}$. En efecto, la visión de conjunto que tiene de la Escritura es el resultado del estudio y sobre todo de la meditación permanente de la misma, lo cual permite que la teología se forje en un diálogo profundo y permanente con aquello que le da consistencia y aporta el elemento diferenciador frente a otros discursos.

La Escritura es asumida también como la autoridad suprema y la paideia propiamente cristiana, que le permite al Niseno configurar su comprensión de Dios, establecer correlaciones intratextuales a partir de la interpretación literal y espiritual, y elaborar la argumentación en la presentación de sus ideas. En el «De anima et resurrectione» que es anterior a la obra objeto del presente estudio, Gregorio se había referido a la autoridad de la Escritura como norma y medida de todos los dogmas en los siguientes términos:

No nos está permitido afirmar lo que nos plazca. La Sagrada Escritura es, para nosotros, la norma y la medida de todos los dogmas. Aprobamos solamente aquello que podemos armonizar con la intención de estos escritos ${ }^{20}$.

18 J. Daniélou, en Grégoire de Nysse, La vie de Moïse ou Traité de la perfection en matiére de vertu (Paris: Du Cerf, 1941), 85 (II, 173). La traducción es nuestra.

19 Cf. M. Canévet, Grégoire de Nysse et l'herminéutique biblique, 72.

20 J. P. Migne, Patrologiae Cursus Completus. Series Graeca. Vol. 46 (Paris: 1863), 50-51. La traducción es de Alberto Múnera, S. J. 
A continuación señalaremos una variedad de ejemplos que dan razón de las ideas antes mencionadas y que pueden servir de referencia en el ejercicio de inculturación de la teología de todos los tiempos.

El primer ejemplo del uso de la Escritura que evidencia la comprensión de la misma como paideia, está presente en el prefacio. Una vez establecido el tema sobre la perfección en la virtud como objetivo de la obra ${ }^{21}$, la primera referencia que hace Gregorio es al apóstol Pablo, a quien reconoce como modelo de virtud cristiana y a cuya autoridad acude para presentar la síntesis de su pensamiento alusivo a la naturaleza de la virtud, afirmando que la perfección en la virtud consiste en no tener límite. Si afirma que «hemos aprendido con el apóstol mismo»22, es porque le reconoce como maestro que cumple una función paidética al enseñar. La expresión usada es la siguiente:

Pero, si se trata de la virtud, hemos aprendido del Apóstol que el único límite de la perfección consiste en no tener límite. Este divino Apóstol, grande y elevado de espíritu, corriendo siempre por el camino de la virtud, jamás cesó «de tender hacia adelante» (Filp 3,13) ${ }^{23}$.

En esta comprensión paidética de la Escritura, es posible situar la articulación que hace Gregorio de la vida de Moisés como modelo de vida virtuosa y que ocupará toda la primera parte de la obra ${ }^{24}$. En la segunda parte, al interpretar la escena de la pelea del egipcio contra el hebreo, en la cual Moisés toma partido por el hebreo, usa la expresión: «Moisés nos enseña por su ejemplo a ayudar a la virtud, como a uno de la propia estirpe y rechazar al adversario que la ataca» ${ }^{25}$. En efecto, esta función pedagógica de la Escritura es central y será retomada en diversos momentos, aunque con diferentes expresiones.

En la escena del maná que cae de lo alto, la interpretación que hace Gregorio está referida a equiparar dicho alimento no producido

21 Cf. J. Daniélou, « Préface, 3», en Grégoire de Nysse, op. cit., 2.

22 Ibíd., Préface, 5. Esta referencia al Apóstol en la carta a los Efesios será retomada por Gregorio en el momento de interpretar la escena en la cual Moisés logra ver la espalda de Dios y comprende que ver a Dios es seguirle. Ibíd., 105 (II, 225).

23 Ibíd. 3. Préface, 5.

24 Ibíd., 8-30 (I, 16-77).

25 Ibíd., 36 (II, 15). 
por el cultivo de la tierra con la Palabra que, gracias a la diversidad de sus cualidades, adapta su fuerza a las capacidades de quienes la comen, por ello no solo se muestra como pan, sino también como leche, carne y legumbres. En esta interpretación evoca la autoridad del apóstol Pablo en los siguientes términos: «Esto es lo que nos enseña Pablo, el divino apóstol, quien nos ofrece en sus obras un alimento, adaptando su palabra en comida sólida para los perfectos, legumbres para los débiles y leche para los niños» ${ }^{26}$.

Un último pasaje ${ }^{27}$ donde es evidente el acento paidético de la Escritura está referido a la interpretación de la serpiente de bronce, que para Gregorio es prefiguración del misterio de la Cruz. La expresión que usa en esta escena es la siguiente: «Que la serpiente en el desierto sea un símbolo del misterio de la cruz, la palabra del Señor lo enseña claramente, cuando dice: «De la misma manera que Moisés elevó la serpiente en el desierto, de igual manera el Hijo del Hombre fue elevado» Jn 3,14» ${ }^{28}$.

\subsubsection{La Tradición}

Otro de los elementos que opera como fuente dentro del teologizar del Niseno es la referencia a la Tradición. En efecto, el obispo de Nisa lee la Escritura en el horizonte de los Padres que le antecedieron ${ }^{29}$, no apegándose de manera neutral o acrítica a las ideas, sino buscando avanzar con un espíritu de libertad en la develación del sentido que subyace a la misma. Pero cuando en el momento de dar razón de la fe los argumentos no son presentados de manera sólida y clara, recomienda continuar con la tradición recibida.

26 Ibíd., 73 (II, 140).

27 Otros pasajes en donde se evidencia la comprensión de la escritura como paideia son los siguientes: Ibíd., 49 (II, 65), 58 (II, 93. 96), 65 (II, 118), 70 (II, 133).

28 Ibíd., 120 (II, 277).

29 Según Daniélou, «Grégoire est l'héritier de toute une tradition qui par Clément et Origène a commencé d'élaborer une théologie mystique en même temps qu'une théologie dogmatique». J. Daniélou, Platonisme et Théologie Mystique, essai sur la doctrine spirituelle de saint Grégoire de Nysse (París: Aubier, 1944), 6-7. 
El referente explícito a la tradición se encuentra en la interpretación que hace Gregorio del encuentro entre Moisés y su hermano Aarón, en la cual evoca la doctrina del ángel custodio que se difundía desde los primeros tiempos del cristianismo. La expresión usada es la siguiente: «Para no explicar el misterio por medio del misterio, expondré más abiertamente el sentido de este pasaje. Hay una doctrina digna de ser creída, que tiene su autoridad en la tradición de los Padres» ${ }^{30}$.

Si bien en la época de Gregorio no existe una sistematización amplia sobre el tema de la tradición, ya se encuentra una referencia directa a la tradición de los Padres reconocida como digna de fe y de autoridad en la Iglesia. Para Gregorio la tradición no opera como una catarata congelada que nunca se modifica, debido a que todo lo que hace parte del mundo tiene como característica el cambio permanente. Ahora bien, las nuevas comprensiones deben garantizar la solidez en los argumentos que implica un esfuerzo de creación audaz, la claridad de los planteamientos que surge de una actitud de reflexión íntima y, contribuir a ampliar la comprensión del sentido que se vehicula en la tradición como garantía de unidad y fidelidad espiritual.

Una idea que es común en los Padres y que está presente en Gregorio es la certeza de su fidelidad a la verdad revelada, expresada en su correspondencia con la verdad ofrecida por el Evangelio, como manifestación viviente de la teoría en la práctica, del saber en el obrar. El obispo de Nisa ve en San Pablo y en su hermano Basilio los modelos a seguir en esta apropiación de la verdad, que es Dios mismo, la Trinidad Santa que ha sido revelada a la humanidad.

\subsubsection{La encarnación}

En la teología contemporánea el título que debería encabezar el presente apartado sería el de «La Revelación», pero en el contexto de los Padres de la Iglesia de los primeros siglos y particularmente en el siglo IV, es imposible encontrar una elaboración equivalente por

30 J. Daniélou, en Grégoire de Nysse, op. cit., 43(II, 45). 
diversas razones, entre ellas, porque para los Padres la revelación es una realidad obvia y no ven en ella un problema en el cual ahondar. Ellos todavía se encuentran bajo la impresión de la gran epifanía de Dios en Jesucristo y la necesidad de proclamar al mundo entero el acontecimiento desconcertante, inaudito, de la irrupción de Dios en la carne y en el mensaje de Cristo.

Por esta razón, el énfasis del presente apartado está referido a la encarnación, que si bien no reemplaza el tema de la revelación, sí permite comprender el acontecimiento culmen hacia el cual se orienta la revelación misma: Jesucristo, verdadero Dios y verdadero Hombre, cima y consumación de la historia de la salvación, Verbo de Dios, Hijo del Padre que asume todos los caminos de la encarnación, tanto la palabra como la acción, para darnos a conocer al Padre y su designio de salvación.

Desde la comprensión de la encarnación como expresión por excelencia del desocultarse de Dios, no existe ninguna verdad real que no deba ser encarnada en una acción, en un camino. Para Gregorio es la encarnación de Cristo la que se constituye en criterio de toda verdad real, y es el caminar en dicha verdad aquello que le permite al creyente acceder a la misma. El proceso realizado por Moisés guiado por la nube y la ley como prefiguración de Cristo, fue la que le permitió sortear las dificultades que se hicieron presente y poder llegar a conocer y contemplar la verdad. Ahora bien, fue esa unidad entre el conocimiento y la vida, aquello que capacitó al Niseno para realizar con creces su ministerio apostólico y el trabajo escriturístico de dar cuerpo a la doctrina cristiana, en otras palabras, aquello que vivió le permitió conocer y dar cuerpo a lo que enseñó y escribió.

Es oportuno señalar que el obispo de Nisa no distingue diferencias entre la encarnación y la redención, debido a que, según Daniélou, para él «La encarnación es redentora, y la redención no es más que el culmen de la encarnación ${ }^{31}$. Además, esta referencia

31 J. Daniélou, Le IV siecle Gregoire de Nysse et son milieu (Paris: Institut Catholique, 1974), Livre II, 102. 
a la encarnación no solo orienta el trabajo escriturístico sino que, como se había mencionado en el capítulo anterior, se convierte en el leitmotiv que dinamiza el actuar del Niseno disponiéndolo al diálogo con la cultura pagana y las diversas realidades sociales y eclesiales que tuvo que afrontar.

La experiencia del Niseno permite evidenciar que la inculturación de la teología solo es posible, en la medida que se asume con todas las implicaciones la dinámica de la encarnación. Lo anterior debido a que es ella la que hace posible la destrucción del maligno, que el hombre sea liberado y pueda por medio del camino de la virtud conocer a Dios y recuperar su imagen original como imagen de Dios.

Una expresión ${ }^{32}$ que permiten entrar en la lógica de comprensión de la encarnación propia del Niseno, en la cual se nota su forma particular de integrar historia, economía y teología, en cuanto parte de un acontecimiento de la historia y lo sitúa dentro del plan de Salvación, dando razón de la manifestación de Dios, es el siguiente:

La ley y los profetas han proclamado el misterio de la Encarnación, pero estos sonidos eran demasiado débiles para alcanzar oídos indóciles: también porque tenían el oído duro, los judíos no percibieron el sonido de las trompetas (...) en cuanto a los instrumentos, estos son los Profetas y los Apóstoles resonando bajo el soplo del Espíritu. Como está escrito en el salmo, "su voz resplandece sobre toda la tierra y sus palabras hasta los extremos del mundo» $\left(\right.$ Sal 18,5) ${ }^{33}$.

\subsection{Características}

\subsubsection{Carácter trinitario de la teología inculturada}

La teología inculturada elaborada por el obispo de Nisa tiene un carácter trinitario, en cuanto constituye el misterio del cual todo brota, se esclarece y se reduce. Lo anterior, no solo porque fue un tema central en su trabajo escriturístico en defensa de la fe de Nicea, sino porque sus obras tienen la referencia a la Trinidad como tras-

32 Otros ejemplos se encuentran en J. Daniélou, en Grégoire de Nysse, op. cit., 37(II, 20), 39(II, 27), 119 (II, 276)

33 Ibíd., 80 (II, 159). 


\section{fondo. Para él, en continuidad con el apóstol Juan, la esencia divina es incomprensible ${ }^{34}$ :}

Es por esta razón que Juan el místico, quien penetró en la tiniebla luminosa, dijo que «ninguna persona ha visto jamás a Dios» (Jn 1, 18), definiendo por esta negación que el conocimiento de la esencia divina es inaccesible no solo a los hombres, sino también a toda naturaleza intelectual ${ }^{35}$.

\section{Pero no pasa lo mismo con las Personas Divinas ${ }^{36}$ en cuanto a su} existencia, sus atributos, que pueden ser conocidos por revelación debido a su acción en el mundo ${ }^{37}$ :

Se trataría entonces de la admirable armonía del mundo que grita la sabiduría que resplandece en el universo y proclama la grandeza de la gloria de Dios, quien se manifiesta en las cosas visibles según la palabra: «Los cielos proclaman la gloria de Dios» $\left(\right.$ Sal 18, 2) ${ }^{38}$.

\section{Y por su reflejo en el espejo del alma que es propio del conoci-} miento místico:

Quien ha purificado el oído del corazón percibe este sonido -entiendo por este, la contemplación del universo que lleva al conocimiento del poder divino-y por él es conducido a penetrar en espíritu allá donde está Dios. Este lugar es llamado «tiniebla» por la Escritura, para significar, como se ha dicho, la incognoscibilidad e invisibilidad. Una vez llegado allá, el contempla el tabernáculo no hecho por mano de hombre y mediante una imitación material la da a conocer a los que están abajo ${ }^{39}$.

En continuidad con lo anterior es oportuno recordar en relación al Niseno que, según Daniélou, «Él es el gran autor de la trascendencia divina. Él da a la doctrina de analogía su expresión filosófica más

34 Aquí se encuentra el punto de partida de la teología apofática.

35 Ibíd., 81-82 (II, 163). Más referencias sobre el tema de incomprensibilidad de la esencia de Dios en II, 164.165.232.233.234.236.239.242.

36 Cf. J. Daniélou, J. Le IV siecle Gregoire de Nysse et son milieu, op. cit., Livre II. 25. Aquí se ubica encuentra el punto de partida de la teología positiva o simbólica.

37 Según Moutsoulas, la distinción entre la esencia divina, que es incompresible, y las energías, de las cuales el hombre puede participar, había sido puesta en evidencia antes de Gregorio de Nisa. Concretamente, Clemente de Alejandría señalaba que la palabra humana es incapaz de expresar la esencia de Dios y que solo la fuerza y las obras de Dios pueden ser conocidas. Un poco antes de él, Ireneo refutaba la pretensión de los gnósticos de poder conocer la esencia de Dios. E. Moutsoulas, Esencia y energías de Dios según San Gregorio de Nisa. Consultada en julio 18, 2013.www.ecclesia.com.br/ Biblioteca/teologia/esencia_Y_energias_de_dios_segun_San_gregorio_de_nisa.html.http://www.ecclesia.com.br/Biblioteca/teologia/esencia_y_energias_de_dios_segun_San_gregorio_de_nisa.html.

38 J. Daniélou, en Grégoire de Nysse, op. cit., 83 (II, 168).

39 Ibíd., 83-84 (II, 169). 
profunda (...) En él, la teología trinitaria definida por el concilio de Nicea, encuentra su expresión más acabada» ${ }^{40}$.

A continuación señalaremos algunos ejemplos de la manera como el Niseno integra la referencia a la Trinidad en el desarrollo de su exposición sobre la vida de Moisés. El punto de partida se encuentra en la evocación a Dios como guía en la elaboración de la argumentación en torno al tema que le han solicitado sobre la perfección en la virtud: «emprendamos ahora nuestro trabajo pidiendo a Dios su guía» ${ }^{41}$.

En la interpretación del encuentro con el ángel, para señalar que quien avanza en la búsqueda de la virtud no está solo, sino que cuenta con la ayuda de Dios para superar las dificultades propias del camino:

Porque es real que aquellos que practican la virtud participan de la asistencia dada por Dios a nuestra naturaleza, asistencia que ya existía antes de nuestro nacimiento, pero que se muestra y se da a conocer cuando nos familiarizamos con una vida más elevada por el progreso y la aplicación, y cuando nos despojamos en función de combates más fuertes ${ }^{42}$.

En la interpretación de las vestiduras sacerdotales cuya elaboración es tejida con la práctica de la virtud, Gregorio hace una referencia explícita a la Trinidad en cuanto que su predicación debe estar acompañada por la fe en Dios y una vida recta.

La perfección está constituida por la unión de dos cosas, la fe en Dios y una vida según la conciencia. Estas son las granadas y las campanillas que el gran Pablo ata al vestido de Timoteo, cuando le dice que debe tener fe y buena consciencia. Que la fe, pues, deje oír un sonido puro y poderoso en la predicación de la Santa Trinidad ${ }^{43}$.

La forma de integrar la comprensión de la Trinidad en el tema de la perfección en la virtud es asumida desde la perspectiva de la Historia de Salvación. En este sentido se hace evidente la referencia a la acción creadora del Padre, la acción redentora del Hijo y la acción

40 J. Daniélou, J. Le IV siecle Gregoire de Nysse et son milieu, op. cit., Livre II. 25.

41 J. Daniélou, en Grégoire de Nysse, op. cit., 2 (Préface, 3).

42 Ibíd., 43 (II, 44).

43 Ibíd., 93 (II, 192). 
santificadora del Espíritu. Particularmente, en la interpretación de la escena de la destrucción de las tablas de la ley por parte de Moisés debido a la idolatría en la que había caído el pueblo, Gregorio integra este hecho dentro de la Historia de Salvación evocando la acción de las tres personas de la Trinidad.

El punto de partida del Niseno es la convicción según la cual en el inicio la naturaleza humana moldeada por las manos divinas ${ }^{44}$ era inmortal y estaba sin fracturas, embellecida con los caracteres no escritos de la ley debido a que estaba dentro de nosotros.

La naturaleza original del hombre estaba sin fracturas y era inmortal, moldeada por las manos divinas, y embellecida con los caracteres no escritos de la ley: la conformidad de nuestra voluntad con la ley estaba inscrita en nuestra naturaleza con el apartamiento del mal y el respeto por las cosas divinas ${ }^{45}$.

Después vino el pecado, que constituye el contexto en el cual se rompen las tablas de la ley y, desde una lectura cristológica de la acción de Moisés, entendida como prefiguración de Cristo, evoca el misterio de la encarnación para hacer referencia a la nueva creación en Cristo que es obra del Espíritu. Según el Niseno «Después de este acontecimiento, la naturaleza fue de nuevo irrompible, volvió a ser inmortal por la impresión del dedo: el dedo, es el nombre que la Escritura muchas veces da al Espíritu Santo» ${ }^{46}$.

\subsubsection{La comunidad eclesial como sujeto de la inculturación de la teología}

La interpretación que hace Gregorio sobre la vida de Moisés en sus diferentes etapas, deja al descubierto que en el proceso de conocimiento de Dios y de crecimiento en la virtud no solo se requiere de la ayuda de Dios, sino también del compartir la existencia y la experiencia de fe con otros, en este caso tanto Moisés con el pueblo de Israel, como el obispo de Nisa con su Iglesia de la región

\footnotetext{
44 En el contexto de los Padres de la Iglesia se conoce como «manos divinas» al Hijo y al Espíritu.

45 Ibíd., 101 (II, 215).

46 Ibíd., 101-102 (II, 216).
} 
de Capadocia. En efecto, dicho proceso es una aventura existencial en la cual se interrelaciona lo personal y lo comunitario como dos dimensiones que si bien se pueden diferenciar, no se entiende la una sino en cuanto referida a la otra.

El teologizar del Niseno es un ejercicio que se realiza en la Iglesia y para la Iglesia, en obediencia a la fe que busca entender desde una actitud orante y contemplativa de la vida, por este motivo, no es de extrañar que en la interpretación que hace de diversos pasajes de la historia de Moisés, el trasfondo esté relacionado con situaciones que vive o ha tenido que vivir en la Iglesia. A continuación mencionamos algunos ejemplos que permiten comprender mejor lo anteriormente dicho.

La interpretación del hecho según el cual Moisés a pesar de vivir con la hija del faraón, continuaba alimentándose de la leche de la madre natural, le lleva al Niseno a concluir como enseñanza que:

Si frecuentamos la cultura pagana en el tiempo de nuestra educación, no debemos privarnos de la leche que nos alimenta, que es la Iglesia. Esta leche son los sacramentos que alimentan nuestra alma, la fortalecen y le dan fuerzas para elevarse hacia lo alto ${ }^{47}$.

Al interpretar la escena en la cual Moisés, después de haber vivido la experiencia de iluminación en la Zarza, habla al pueblo valerosamente acerca de la libertad, la enseñanza con la cual concluye es «no tener la presunción de hablar al pueblo sin haber tenido una larga preparación que hubiese puesto nuestra palabra en condiciones de abordar a las grandes asambleas ${ }^{48}$. Lo anterior permite comprender mejor por qué era de suma importancia el tema de la educación para los capadocios.

Otra idea importante para la comprensión del tema en cuestión tiene que ver con la interpretación de la escena en la cual el pueblo encarga a Moisés que conozca por sí mismo los misterios ocultos y posteriormente comunique al pueblo la doctrina que haya aprendido 
a través de la enseñanza divina. Gregorio relaciona esta escena con la práctica que se tiene en la Iglesia:

Todos no procuran penetrar en la inteligencia de los misterios, sino que eligen a alguien que sea apto para percibir las cosas divinas y le prestan voluntariamente su oído, juzgando digno de fe todo lo que han escuchado de quien ha sido iniciado en los misterios divinos ${ }^{49}$.

A partir de los ejemplos antes mencionados es posible comprender mejor que el sujeto de la inculturación de la teología es la comunidad. Gregorio no escribe para él mismo, sino para la comunidad con la cual vive y comparte la fe, ni entiende su quehacer teológico al margen de la comunidad, sino como miembro de ella, en este caso como su cabeza debido a su función de obispo.

\subsubsection{La función del teólogo como testigo en la inculturación de la teología}

En Gregorio de Nisa como en los otros dos capadocios la educación cumple una función determinante, no solo en el ejercicio teológico sino también en el apostólico debido a que en este momento la teología es realizada por obispos. En la interpretación de la cestilla en la cual los padres de Moisés lo depositan para liberarlo de la muerte, la referencia directa es a la educación, que cumple la función de cestilla para lograr que sobre las olas de la vida, la persona logre mantenerse a flote y evitar que se equivoque mucho y se hunda.

Esta cesta, hecha de juncos trenzados juntos representa la educación, que resulta de diversas disciplinas. Ella mantiene por encima de las agitaciones de la vida a aquel que lleva; gracias a ella, él no errará por la agitación del mar sino que arribará al puerto, rechazado por el movimiento mismo de las aguas hacia el litoral donde saldrá del océano de la vida ${ }^{50}$.

La educación para el Niseno debe ser amplia, pero ante todo debe orientarse en función del crecimiento en la virtud y al servicio de la fe. Bajo este criterio, es posible comprender mejor la razón por la cual para el obispo de Nisa no debe atreverse a hablar ante el pueblo 
aquel que no haya sido cultivado con una educación adecuada ${ }^{51}$. Además, por la correlación que se establece entre conocimiento de Dios y vida virtuosa, el teólogo debe buscar mantener el equilibrio entre aquello que su apertura a la gracia le permite conocer de Dios y la rectitud de su vida, en otras palabras, promover en él mismo la integración entre la ortodoxia y la ortopraxis. Más aún, el teólogo debe esforzarse por buscar la perfección que es posible aspirando a una vida más elevada, cumpliendo una función de guía por su testimonio, a la manera de Moisés, para conducir a sus semejantes al conocimiento de Dios $^{52}$.

Sobre el valor y la importancia del testimonio hay una alusión significativa en la interpretación que realiza el Niseno sobre el sacerdocio:

Si tú ves que la vida de un sacerdote es placentera, dulce y color de rosa, como es el caso de muchos que se visten de lino y de púrpura, que se engordan en mesas espléndidas, que beben un vino escogido, se ungen con los mejores perfumes y usan todas otras cosas que halagan los sentidos de quienes recogen los goces de la vida, tu podrás decir con toda exactitud la palabra del Evangelio: «viendo el fruto, no reconozco el árbol sacerdotal» $(\text { Lc } 6,43)^{53}$.

En este orden de ideas el teólogo debe, a partir de su experiencia de conversión, buscar el equilibrio ejercitando la virtud de la templanza apoyado en la vivencia de una fe madura, logrando con ello apropiar la sabiduría necesaria para vivir la vida según conciencia. Profundizar en la meditación de la Escritura, particularmente del mensaje evangélico, afianzándose en la adhesión a Cristo, quien lo capacita para afrontar las dificultades de la vida. Alimentarse con la celebración de los sacramentos, particularmente de la Eucaristía, asumir una actitud orante de la vida y de esta manera ser llevado a la contemplación de la naturaleza que todo lo trasciende ${ }^{54}$.

54 Los elementos mencionados hacen parte de la interpretación que hace el obispo de Nisa de la escena de la subida al monte Sinaí. Cf. Ibíd., 77-78 (II, 152.153.154.155). 
En la lógica del Niseno la misión es clara, si por el pecado el hombre distorsionó su naturaleza como imagen de Dios, dicha imagen fue restablecida por Jesucristo en el misterio de la encarnación. Por esta razón quien a la manera de Moisés, como prefiguración de Cristo, avanza en el crecimiento en la virtud con una vida recta y la iluminación recibida por la contemplación del misterio, siente la necesidad de guiar a sus compatriotas a una vida en libertad, que para Gregorio es propia de quien es imagen de Dios. Sobre las ideas anteriormente expuestas el referente se encuentra en un pequeño resumen de la enseñanza que ha dejado la interpretación de la historia de Moisés, que sirve de antesala para abordar la escena de la muerte de los primogénitos:

Como Moisés -y aquel que a su ejemplo se eleva en la santidad-cuando su alma se encontraba fortalecida por una larga aplicación a una vida austera y celeste y por la luz de lo alto, juzgó que sería una falta de su parte no hacerse a su vuelta el guía de sus compatriotas hacia la libertad ${ }^{55}$.

El desarrollo de la misión del teólogo se realiza con la presencia de dificultades referidas a: a) La envidia, que se desata contra aquel que avanza en el conocimiento de Dios y en la virtud ${ }^{56}$. El mismo Niseno tal como se comentó en los capítulos anteriores, fue víctima de dicha pasión malvada a través de maquinaciones y engaños en el ejercicio de su labor apostólica por parte de los obispos arrianos. b) Las tentaciones, que desvían hacia el mal o a ser dominado por las pasiones y los placeres materiales, pero frente a las cuales, como afirma Gregorio «los hombres sostenidos por el socorro divino son superiores a toda tentación $»^{57}$. c) El orgullo, en el cual suelen caer quienes se mofan de sus buenas acciones considerándose mejores que los demás y, enceguecidos por su soberbia, corroboran según Gregorio «la descripción que define el orgullo: una subida hacia abajo» ${ }^{58}$.

56 El obispo de Nisa dedica varios apartados de su obra para abordar el tema de la envidia. Ibíd., 114115 (II, 256-261).

57 Ibíd., 125 (II, 292).

58 Ibíd., 121 (II, 281). 
Frente a la presencia de las tentaciones, Gregorio invita a mantener siempre una postura irreprochable y permanecer con la mirada fija en la cruz de Cristo, roca firme, quien capacita para afrontar cualquier tipo de tentación. Además, evocando el testimonio de Moisés, quien fue digno de ser llamado servidor de Dios, exhorta a tener por digno solo una cosa, "A no tener más que un fin en esta vida, ser llamado servidor de Dios a causa de nuestras acciones ${ }^{59}$.

\subsubsection{Teología inculturada como búsqueda de sentido espiritual}

En Gregorio de Nisa la teología se concibe como la fe que busca entender. En esta inteligencia de la fe ningún elemento de la realidad está vedado, debido a que a partir del misterio de la Encarnación toda la realidad fue asumida en el Hijo y anhela su redención. En este orden de ideas, la realidad cumple una función reveladora que necesita ser interpretada para desentrañar el sentido espiritual que le subyace y que contribuye a posibilitar el conocimiento de Dios.

Ahora bien, debido a que, por un lado, la realidad es dinámica al estar sometida al cambio permanente por tener como característica la finitud y, por otro lado, a que para Gregorio la infinitud constituye la cualidad misma de Dios, el quehacer teológico es, por esta razón, un ejercicio en constante elaboración en procura de avanzar en la comprensión del sentido espiritual presente en la realidad histórica, que posibilita una más adecuada inteligencia de la fe. En este sentido, según Daniélou, «La teología ha de ser la patria de la libre investigación y la guardiana de un tesoro que se le ha confiado» ${ }^{60}$.

Lo anterior permite comprender mejor la forma de proceder del Niseno y la correlación que establece entre historia, economía y teología. Esa importancia que le da a la historia como punto de partida de su teologizar permite comprender, según Illanes, que «la historia no es un mero sucederse de acontecimientos que, una vez acaecidos, se hunden en el vacío, sino una historia de hombres, de seres que,

60 J. Daniélou, «Responsabilidades de la teología actual», Selecciones de teología 1-2 (1962): 1. 
al ser espirituales, trascienden el tiempo y pueden vencer la muerte y permanecer durante toda la eternidad $\nu^{61}$.

El primer ejemplo en el cual se puede verificar lo dicho anteriormente se encuentra en el prefacio, particularmente en el cierre del mismo y antesala de la primera parte:

En este caso, tomamos a Moisés por modelo. Daremos primero una visión de conjunto rápida de su vida, tal como la Escritura nos lo hace saber. Luego buscaremos el sentido espiritual que corresponde a la historia, para encontrar allí una regla de virtud. Y de esta manera aprenderemos a conocer lo que es para los hombres la vida perfecta ${ }^{62}$.

En el momento de interpretar el encuentro de Moisés con Aarón, quien aparece en la escena en procura de su ayuda, Gregorio afirma: «Para no tener que explicar un misterio con otro misterio, expondré más abiertamente el sentido de este pasaje ${ }^{63}$. Otra referencia explícita a la búsqueda del sentido espiritual se evidencia en la interpretación que realiza del fenómeno de la plagas de Egipto: «Comencemos por comprender de modo general el fin de estos milagros hasta el punto de vista espiritual, pues de esta manera nos será posible encontrar el sentido conveniente de cada uno de ellos en particular» ${ }^{64}$.

\subsubsection{El método como referente en la búsqueda de sentido espiritual}

El presente apartado no busca determinar un método exclusivo que deba ser apropiado por el teólogo para realizar el ejercicio de inculturación de la teología, sino simplemente mostrar la manera como el Niseno hizo uso de un método para concretar aquello que es propio de la teología, esto es, desentrañar el sentido, la significación y el valor trascendente de la existencia humana a partir de su experiencia de fe. El método seguido por Gregorio lo constituye la Akolouthia, entendida como una coherencia, secuencia de racionamientos de carácter explicativo y argumentativo que aseguran el

61 J. L. Illanes, Historia y sentido. Estudios de Teología de la historia (Madrid: Rialp, 1997), 49.

62 J. Daniélou, en Grégoire de Nysse, op. cit., 6 (Préface, 15).

63 Ibíd., 43 (II, 45).

64 Ibíd., 49 (II, 65). 
carácter científico del conocimiento a través de la reducción a los primeros principios.

Las expresiones que avalan la anterior caracterización del método son las siguientes:

Pienso que, para quien es iniciado en la simbólica de la historia, la coherencia del progreso en la virtud que hemos expuesto aparece claramente siguiendo el concatenamiento de los símbolos ${ }^{65}(\ldots)$ Pero seguimos el hilo de nuestra explicación para tratar de tomar alguna cosa del significado espiritual de este pasaje ${ }^{66}$ (...) Esta interpretación concuerda con lo que habíamos explicado acerca de Aarón ${ }^{67}$.

En la obra objeto del presente estudio se hace evidente el esfuerzo por parte del autor, para que su escrito no se distorsione o altere o se torne repetitivo, sino para que a través de la interpretación de cada escena se aporte algo nuevo que ayude a una mejor comprensión del tema y a identificar sus principios fundamentales, que en el caso de la historia de Moisés está constituido por las tres teofanías que van a ser interpretadas como las tres etapas en el conocimiento de Dios o en la perfección en la virtud, debido a la unidad que se establece entre estos dos elementos.

En el desarrollo de la Akolouthia Gregorio se esfuerza para que la argumentación sea lo suficientemente clara y coherente, al punto que si hay algo que no se corresponde dentro de la narración, él mismo sugiere que se rechace todo: «Quien no crea que existe una total correspondencia entre la recitación histórica y su interpretación espiritual, si encuentra algún detalle que no concuerda con la interpretación, tiene pretexto para condenar todo» ${ }^{68}$. Además, si existe algún elemento en la consideración de la historia cuya interpretación no aporta al tema central objeto de estudio, recomienda pasarlo por alto y no interrumpir la coherencia: «Si alguno de los acontecimientos mencionados por la historia no puede ajustarse con el contexto de la interpretación espiritual, lo consideraremos inútil para nuestro 
trabajo y continuaremos la exposición, a partir de los episodios que son susceptibles de ser aplicados a la virtud $»^{69}$.

\subsubsection{Teología inculturada como expresión del seguimiento de Cristo}

El ejercicio de inteligencia de la fe que es propio de la teología en su esfuerzo por inculturarse, tiene como espacio existencial de gestación el seguimiento de Dios o de Cristo que implica el ejercicio de la propia libertad para hacer posible el proceso de transformación en Él. En este sentido, es en Cristo, en el encuentro con Él en la dinámica de seguimiento, que implica no solo tener sus mismos sentimientos, sino participar también en los misterios de su vida, como el hombre se encuentra con la divinidad. En la interpretación que hace Gregorio de la tercera teofanía, donde Dios se manifiesta a Moisés en la hendidura de la roca, a la cual ha llegado después de haber avanzado por el camino que representa al Unigénito de Dios en quien se contiene todo bien, sintió el llamado y le fue concedido ver la espalda de Dios ${ }^{70}$. En clave de paideia deduce el Niseno la enseñanza que recibió Moisés sobre la manera como es posible ver a Dios:

La enseñanza que recibe Moisés, procurando ver a Dios, de la manera que esto es posible es esta: seguir a Dios a donde quiera que conduzca, en esto consiste el ver a Dios. En efecto, «su paso» significa que conduce a aquel que le sigue. No le es posible al que ignora el camino viajar con seguridad si no sigue al guía. El guía le muestra el camino precediéndole. El que sigue no se apartará del buen camino, si siempre está orientado hacia la espalda del que lo conduce ${ }^{71}$.

En este orden de ideas, si a Dios revelado en Cristo, quien constituye la fuente de la fe, se le conoce siguiéndolo, la teología tiene como función dar razón de dicho seguimiento para iluminar la vida de los creyentes que tienen como tarea el seguimiento de Cristo. Esta realidad del seguimiento al ser dinámica debido a que se realiza en la historia, cuyos contextos son diversos y las coyunturas históricas 
son variables, exige por parte de la teología un ejercicio continuo y renovado de dar razón de la fe.

\subsubsection{Teología inculturada como ejercicio narrativo, especulativo y místico}

Las ideas antes mencionadas sirven de base para comprender la manera como en el teologizar del obispo de Nisa, se integra lo narrativo que da cuenta de la experiencia histórica personal y comunitaria, el ejercicio especulativo de la razón y la apertura de la interioridad que remite a la experiencia mística. Estos tres elementos ponen en evidencia la variedad de horizontes que puede asumir el quehacer teológico siempre teniendo como referente fundamental la Escritura que constituye la paideia propiamente cristiana ${ }^{72}$.

Dentro de toda la obra del Niseno es posible rastrear la forma como hace uso de dichos horizontes colocando mayor acento en alguno de ellos; al respecto, es posible evidenciar un acento narrativo refiriendo como ejemplo las homilías, los sermones y panegíricos, un acento especulativo que puede ejemplificarse en las disputas con los herejes, particularmente en el Contra Eunomio y el Contra Apolinar, y un acento místico al cual se puede señalar como ejemplo el comentario al Cantar de los Cantares. Además, como algo característico del Niseno, se da la posibilidad de integrar los tres horizontes antes mencionados en el desarrollo de un mismo escrito, tal es el caso de la obra objeto del presente estudio: «De Vita Moysis». A continuación se describirá un poco más la forma como se realiza la integración de dichos horizontes.

En el inicio del prefacio de la obra el horizonte es narrativo y le permite aprovechar el ejemplo de las carreras de caballos para establecer una relación con el pasaje bíblico de la carta a los Filipenses y señalar el tema central que orientará el escrito, la perfección en

72 Según Patiño, «El ministerio de la Padres está al servicio de la Palabra, pero dado que la Palabra se ha hecho carne, el anuncio se amplía y proyecta a los aspectos concretos de la vida humana iluminándolos. Por esto su teología hace una permanente relación entre la Palabra y la vida, entre la Palabra y el acontecer histórico». J. U. Patiño, Los Padres de la Iglesia. Una tradición como búsqueda teológica (Bogotá: San Pablo, 2005), 163. 
la virtud. Al iniciar el proceso de argumentación apela en primera instancia a la Escritura para afirmar en referencia al apóstol Pablo, que el único límite de la perfección es no tener límite, de lo cual se deriva la imposibilidad de alcanzar la perfección ${ }^{73}$.

Ahora bien, para ampliar más la explicación sobre lo inalcanzable de la perfección, pasa del horizonte narrativo al especulativo echando mano del aporte de filósofos tales como Platón, Plotino, para argumentar la infinitud de Dios y la correlación que se establece entre el bien y Dios que le permiten afirmar que quien busca la virtud no busca otra cosa que a Dios, quien es la virtud perfecta. Frente a la imposibilidad de alcanzar la perfección, por cuanto el bien y Dios son ilimitados, el Niseno pasa de nuevo al horizonte narrativo y, nuevamente se remite a la Escritura para identificar la perfección que es posible, señalando como alternativa el estar siempre dispuestos conseguir un mayor bien, refiriendo como ejemplo a los Santos ${ }^{74}$.

El horizonte narrativo se despliega durante toda la primera parte en la presentación de la historia de Moisés como modelo de vida virtuosa. En la segunda parte el énfasis lo tendrá el horizonte místico referido a la interpretación alegórica de las tres teofanías, que constituyen las tres etapas en el conocimiento de Dios, con algunas excepciones en las cuales pasa al horizonte especulativo, para argumentar sobre el tema de la libertad ${ }^{75}$, la noción de verdad ${ }^{76}$, las partes del alma ${ }^{77}$, la incorruptibilidad de la naturaleza divina ${ }^{78}$, la naturaleza ilimitada de $\operatorname{Dios}^{79} \mathrm{y}$, al horizonte narrativo para realizar los resúmenes del proceso ${ }^{80}$, hacer referencia a los ministerios en la Iglesia ${ }^{81}$, caracterizar los temas de la envidia ${ }^{82}$ y del orgullo ${ }^{83}$.

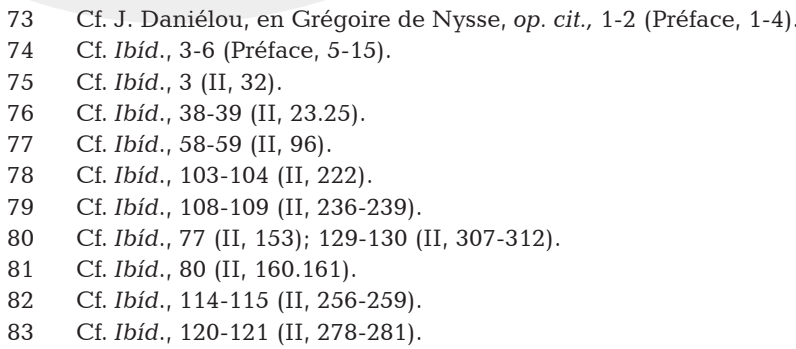


Como complemento a la explicitación de los diferentes horizontes desde los cuales es posible realizar el quehacer teológico, es oportuno señalar la necesidad de correlacionar, dentro de dicho quehacer, la praxis y el ejercicio de contemplación. Precisamente en la interpretación que hace Gregorio de las vestiduras sacerdotales, al referir el significado que tienen las cadenillas que permiten la adhesión de los ornamentos a los brazos, evoca como enseñanza, que «la vida perfecta exige la unión de la filosofía práctica y el ejercicio de la contemplación, el corazón era el símbolo de la contemplación y los brazos, de las obras» ${ }^{84}$. De acuerdo con todo lo que se ha comentado hasta el momento, es posible señalar que la vida perfecta está en relación con el conocimiento de Dios y, por tanto, con la teología que busca dar razón de dicho conocimiento al cual es posible acceder por la rectitud de la vida.

\subsubsection{Teología inculturada como servicio a la Iglesia}

La teología elaborada por el Niseno se entiende desde el inicio como una labor que se realiza en la Iglesia, encargada de proporcionar al creyente el alimento que fortalece en el crecimiento en la $\mathrm{fe}^{85}$ y para el servicio de la Iglesia en su apertura al mundo y a las diferentes culturas. Tal como fue comentado en el capítulo primero, Gregorio escribe su primera obra sobre la virginidad a solicitud de su hermano Basilio, para darle una fundamentación teológica a la experiencia monacal que se vivía en Annesi. Además, habría que decir que la mayor parte de sus obras, siguen esa misma línea de responder a solicitudes que le hacían sobre temas puntuales o, como en el caso del Hexamerón cuya motivación era la de continuar el trabajo iniciado por Basilio, o continuar la defensa de la fe de Nicea después de la muerte temprana de su hermano, representada en los doce libros que dan cuerpo a la obra conocida como "Contra Eunomio».

La teología del obispo de Nisa, quien ha asumido a fondo el misterio de la encarnación, es propuesta como un servicio a la Iglesia 
a la cual reconoce como cuerpo de Cristo y, por esta razón, como Tabernáculo terreno:

Pasemos ahora a la contemplación del tabernáculo inferior. Dado que Pablo identifica en numerosos lugares a la Iglesia con Cristo, podríamos entender a los servidores del divino Misterio, que el Verbo llama «columnas» de la Iglesia, a los apóstoles, los doctores y los profetas ${ }^{86}$.

Dicho servicio se realiza en procura de promover la inteligencia de la fe en el diálogo con la cultura, razón por la cual hace uso de ejemplos cercanos a las personas, como el de las carreras de caballos, que fue citado en un apartado anterior para comprender el proceso de búsqueda de la virtud; la referencia a los personajes bíblicos en función de encaminar hacia la vida virtuosa, concretamente la vida de Moisés ${ }^{87}$. Además, busca ajustar el mensaje a las capacidades de quienes lo reciben ${ }^{88}$, cumple una función profética para alzar la voz frente a situaciones que desvirtúan la $\mathrm{fe}^{89}$, apela a un lenguaje performativo que insta al lector a apropiar aquello que se le ha mostra$\mathrm{do}^{90}$ y asume una referencia directa a los sacramentos debido a que a través de ellos se dinamiza el proceso de crecimiento en la fe y la práctica de la virtud; además, para el Niseno toda la vida espiritual está inmersa en la vida sacramental que la alimenta, particularmente en los tres sacramentos de la iniciación cristiana ${ }^{91}$.

La finalidad de la función de servicio antes mencionada es apostólica, en orden a la redención, que constituye en Gregorio, la meta de la encarnación. En la interpretación que realiza de la salida de Egipto hay una evidencia de la función liberadora: «He aquí este relato de la salida de Egipto: nos muestra cómo todo hombre que sigue a Moisés debe liberar de la servidumbre a todos los egipcios que guía por su palabra» ${ }^{92}$.

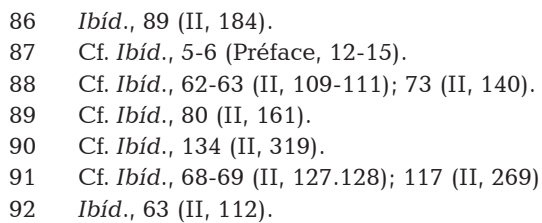


Tal vez el pasaje donde se muestra más explícito el énfasis en lo salvífico se encuentra en la interpretación del episodio de la zarza en la cual Moisés es iluminado por la luz que representa a Cristo y, por esta razón, es «capaz de ayudar también a otros a salvarse, derribando la tiranía de las fuerzas del mal y devolviendo la libertad a todos los que estuvieron sometidos a su esclavitud» ${ }^{93}$.

\subsubsection{Teología inculturada como expresión del diálogo entre teología y cultura}

El elemento fundamental que posibilita el diálogo entre teología y cultura lo constituye el misterio de la encarnación. Fue la comprensión de dicho misterio, aquello que dispuso al Niseno a establecer el diálogo con la cultura pagana y las diversas realidades sociales y eclesiales de su tiempo. En efecto, la encarnación permite comprender que Dios acontece en el espacio-tiempo de los hombres inaugurando el kairós por excelencia: el tiempo de la salvación de Dios para los hombres.

En la interpretación de la procedencia extranjera de la esposa de Moisés se encuentra el criterio que está a la base del diálogo con el mundo, con la cultura. Si por la encarnación, la realidad quedó transida de la trascendencia y cumple por ello una función reveladora de la misma, el criterio para viabilizar el diálogo antes mencionado consiste en que contribuya a engendrar la virtud y el conocimiento de Dios. Por tanto, si la apropiación y el diálogo con la cultura deben realizarse de manera crítica, dicha crítica se orienta en función de discernir aquello que haga posible la apertura a la fe y la vivencia de la misma.

Él será acompañado por su mujer, nacida de una raza extranjera. Hay en la cultura profana algo que no es posible rechazar en la formación en la virtud. La filosofía moral y la filosofía de la naturaleza pueden ayudar a quienes les gustan y las cultivan a elevarse más alto, a condición de que su fruto no retenga nada de la mancha extranjera ${ }^{94}$. 
Vale la pena recordar que para los Padres pertenecientes a la escuela de Alejandría, el problema de la cultura pagana consistía en que no había sido capaz de conducir al verdadero conocimiento de Dios al enseñar,

la metempsicosis y el pasar de un ser espiritual a uno animal (...) enseña la existencia de Dios, pero por otro lado lo cree material; confiesa que es demiurgo, pero añade que necesita la materia para crear el mundo; le atribuye bondad y poder, pero somete el bien de las cosas a la limitación del destino ${ }^{95}$.

Lo anterior sin desconocer la presencia de elementos favorables que podrían ayudar en la búsqueda de la virtud como es el caso de la filosofía moral y la filosofía de la naturaleza. Pero no solo eso, pues en la interpretación de la escena en la cual los israelitas toman elementos de la riqueza de los egipcios, Gregorio señala otros elementos de los cuales es posible aprovisionarse, dándoles una orientación particular en función de adornar el tabernáculo terreno, o en otros términos, colocar la cultura al servicio de Dios.

Conviene dejar el sentido literal para pasar al sentido espiritual y ver allí una orden de la Escritura a aquellos que la virtud ha hecho libres, de aprovisionarse de las riquezas de la cultura profana de la cual los paganos sacan ventaja, como la filosofía moral y la filosofía natural, la geometría y la astronomía, la dialéctica y todas las otras ciencias cultivadas por los paganos; nuestro guía nos ordena sustraer el uso de los egipcios que las poseen para servirnos de ellas, si es el caso, para engalanar el Templo de la Revelación con los tesoros de la sabiduría humana ${ }^{96}$.

Esta forma de establecer el diálogo con la cultura lo había aprendido Gregorio, de los padres de la escuela de Alejandría, particularmente de Orígenes, de quien ya hicimos mención de la carta que envía a su discípulo Gregorio Thaumaturgo indicándole cómo sacar provecho de la cultura en función de la fe, pero como una práctica cercana de la cual fue testigo, la aprendió de su hermano Basilio:

Mucho le aporta a la Iglesia de Dios la cultura profana, como el ilustre Basilio, quien después de haber acumulado en el tiempo de su juventud 
los más bellos tesoros de Egipto, los consagró a Dios para que sirvieran a la ornamentación del verdadero tabernáculo, que es la Iglesia ${ }^{97}$.

\subsubsection{Teología inculturada como ejercicio siempre en construcción}

Todas las ideas que han antecedido la elaboración del presente apartado permiten comprender, por qué la teología no puede concebirse como un ejercicio que se realiza una vez y queda fijado en el tiempo para siempre, como una catarata congelada, sino como un continuo y constante ejercicio de intelección de la fe. En efecto, si según el Niseno lo propio de Dios es ser Infinito, la teología, en tanto momento segundo que sigue del encuentro entre Dios y el ser humano, debe mantenerse siempre abierta a transformar sus contenidos y procedimientos, esto es, permanentemente dispuesta a deconstruir y construir teorías o de lo contrario incurriría en otra forma de idolatría, a purificar y actualizar conceptos, a rememorar y reinterpretar las verdades anunciadas, a reconocer que su palabra siempre será parcial, limitada y nunca definitiva porque no hay nombre capaz de expresar la naturaleza divina.

Esta característica de la teología como ejercicio siempre en construcción, no resulta solo de la referencia a la infinitud de Dios, sino también al carácter finito por parte de quien la elabora. Evocando al Niseno, todo aquello que tiene como característica la finitud está sometido al cambio continuo, razón por la cual necesita engendrarse constantemente a través del ejercicio de la libertad. Por tanto, si la realidad y el teólogo que está inmerso en ella, están sometidos al cambio, es posible deducir que el teólogo debe estar en la búsqueda permanentemente de una mayor inteligencia de la fe, asociada a un proceso personal de crecimiento en la virtud que lo dispone para no errar tanto en el conocimiento de la verdad, a la cual Gregorio relaciona con Dios mismo. Además, en lo que corresponde a la teología en su búsqueda de desentrañar el sentido presente en la realidad, 
debe también recrearse constantemente e ir al ritmo de los cambios que emergen en dicha realidad, buscando servir de guía a quienes en medio de las turbulencias de la vida buscan un bien mayor, es decir, a Dios.

Dentro de la variedad de ejemplos ${ }^{98}$ que permiten corroborar de primera mano lo afirmado anteriormente, damos prelación a los siguientes.

La convicción de Gregorio de que Dios está más allá de todo concepto y de toda palabra le conduce a la relativización de todo discurso y de toda palabra en el terreno teológico. Para Él, la palabra humana nunca expresará con perfección la riqueza del misterio; pero es consciente de la importancia del lenguaje, del servicio que puede prestar a la verdad revelada, de la necesidad de utilizarlo con la mayor exactitud y de que su significado sea entendido por todos. Referimos dos pasajes que dan cuenta de lo afirmado, el primero está situado en la interpretación de la escena de la tiniebla, y el segundo en la interpretación del tabernáculo celeste:

Llegado allí, recibe por la palabra la misma enseñanza que ya le había sido dada antes por medio de la tiniebla, esto, pienso, a fin de afirmar nuestra fe en esta doctrina por el testimonio de la palabra divina. Aquello que rechaza desde el inicio la palabra divina es que los hombres asimilen a Dios a algo que ellos conocen; aprendimos que todo concepto formado por el entendimiento para tratar de alcanzar y cercar la naturaleza divina consigue sólo dar forma a un ídolo, no a hacerla $\operatorname{conocer}^{99}$ (...) Que se llame «tienda» a un bien tan grande no hace que el amigo de Cristo se escandalice, como si el sentido de la expresión rebajara la majestad de la naturaleza divina. En efecto, ninguno de los otros nombres que sirven para designarlo es más digno de Él, pues todos son incapaces de ofrecer una significación exacta, ya sea aquellos con los que se imagina encontrar una idea de grandeza, como aquellos que se consideran de poco valor ${ }^{100}$.

La sensatez y el conocimiento de las limitaciones que contiene el hablar de Dios presentes en el Niseno, le llevan en un momento determinado de la narración, en la cual aborda la interpretación del 
tabernáculo celeste, a señalar el carácter hipotético sobre el cual se mueve y someterla al buen sentido de quienes la oigan, dejando su aceptación o su rechazo al parecer de quien la examine. «Por nuestra parte aquello que diremos sobre este asunto es conjetura e hipótesis y dejamos a juicio de los lectores el rechazar o adoptar según el criterio de su examen ${ }^{101}$.

Para cerrar este apartado es oportuno evocar el aporte de Sergio Zañartu, conocedor de la tradición de los Padres de la Iglesia y quien señala que la necesidad del cambio permanente en la labor conceptual de la teología obedece a que

La fe, comunicada y entregada al hombre en la Tradición, está siempre en busca de inteligencia y de una más adecuada expresión. Así, con esta transformación sucesiva del lenguaje, se va perfilando mejor el contenido de la Revelación. Es la autocomunicación de Dios que se va iluminando con las cambiantes circunstancias ${ }^{102}$.

\section{Conclusión}

La teología cristiana católica es desde sus inicios una aventura existencial que abraza todo el espectro de la vida humana. Solo cuando se entiende así se evita el problema de caer en narrativas vacías, especulaciones que no dan cuenta de la realidad y misticismos desencarnados que no permiten inculturar la teología y, de esta manera, dar verdaderamente cuenta del acontecer de Dios en la historia real de las mujeres y los hombres de cada momento histórico.

Queda claro en el teologizar del Niseno que las fuentes de la teología no son piezas de museo que solo sirven para saber que existen, sino verdaderas vetas inagotables que exigen ser interpretadas permanentemente para ampliar y aclarar cada vez más la comprensión del sentido espiritual que en ellas subyace y que es fuente de vida para la existencia del creyente y de la Iglesia en general. La

101 Ibíd., 85 (II, 173).Ibíd., 85 (II, 173).

102 S. Zañartu, «Revelación, tradición e inculturación: Pautas para un ensayo», Teología y vida 4, Vol. 44 (2003), 497, consultada julio 24, 2013. www.scielo.cl/scielo.php?script=sci_arttext\&pid=S0049$34492003000400007 \& \operatorname{lng}=$ es\&nrm=iso $>$.ISSN 0049-3449.doi:10.4067/S0049-34492003000400007. 
riqueza de la Escritura es inagotable, por más estudios que se han hecho y siguen haciéndose; la Tradición, que es igualmente rica, ha sido subestimada por la falta de una adecuada comprensión de la misma y está a la espera de ser debidamente explorada; y todavía no hemos logrado ahondar en las implicaciones que tiene para la fe y la inteligencia de la misma, la comprensión del misterio de la encarnación, que es la clave fundamental para concebir y realizar la inculturación de la teología.

Si la Escritura es la paideia cristiana por excelencia, el teólogo no solo debe destacarse por el conocimiento científico que pueda lograrse de ella, sino por la constante meditación de la misma, que no solo lo capacita para avanzar en la búsqueda de un bien mayor y avanzar en el conocimiento de Dios, sino también para poder dirigirse y guiar a otros. Definitivamente el testimonio de vida fue esencial en la manera como Gregorio de Nisa hizo posible la inculturación de la teología. Fue una teología realizada en referencia a la santidad de vida, pero santidad entendida como la búsqueda permanente de un bien mayor, pues esa es la perfección a la cual puede aspirar el hombre.

Si se afirma que la teología forma parte del camino del hombre en la Iglesia hacia el último misterio de Dios, también la teología y quien la elabora tiene que peregrinar buscando servir de guía, es decir, tiene que intentar comprender permanentemente la cultura de su tiempo y entrar en un diálogo profundo con ella echando mano de los elementos de la cultura que sean necesarios para comunicar de una manera siempre nueva la inteligencia de la fe.

La inculturación de la teología exige mantener la unidad entre teología y vida espiritual como las dos caras de una misma moneda. En este sentido, solo se puede dar verdadera razón de la fe cuando se vive aquello en lo cual se cree o, en otros términos, a Dios se le conoce siguiéndolo, imitándolo. Las tres teofanías que demarcan las etapas en el conocimiento de Dios, son también las que determinan el proceso de avance en el itinerario espiritual. En el caso de Moisés, 
es el crecimiento en su vida espiritual aquello que lo capacita para llegar a conocer a Dios.

La inculturación de la teología es una actividad que se realiza en la Iglesia y para la Iglesia en su apertura al mundo, pues de la inculturación de la teología depende tanto la inculturación de la fe como de la Iglesia. Además, es un ejercicio siempre en construcción por muchos factores, entre ellos, por ser obra del ser humano que por su condición de finitud está sometido a la contingencia, a la posibilidad del error; por el carácter dinámico de la historia y de la cultura, que se desprende de la afirmación anterior; porque la naturaleza divina es infinita e inabarcable; porque los conceptos siempre son limitados para dar cuenta de la manifestación de Dios; porque la fe es dinámica y desea una mayor comunión con Dios, porque la inteligencia de la fe está limitada por las circunstancias históricas, culturales de cada época y porque las fuentes de la teología exigen ser permanentemente interpretadas para renovarse y ampliar cada vez más la comprensión del sentido espiritual que les subyace.

\section{Bibliografía}

Azevedo, M. Comunidades eclesiais de base e inculturação da fé. São Paulo: Loyola, 1986.

Canévet, M. Grégoire de Nysse et L'hermeneutique Biblique. Paris: Études Agustiniennes, 1983.

Concilio Vaticano II. «Constitución Pastoral Gaudium et Spes sobre la Iglesia en el mundo actual». En Constituciones, decretos, declaraciones. Madrid: BAC, 1966.

Daniélou, J. Le IV siecle Gregoire de Nysse et son milieu. Paris: Institut Catholique, 1974.

. «Responsabilidades de la teología actual». Selecciones de Teología, 1-2 (1962): 1-16. 
. Platonisme et théologie mystique, essai sur la doctrine spirituelle de saint Grégoire de Nysse. París: Aubier, 1944.

De Franca Miranda, M. La inculturación de la fe: Un abordaje teológico. Bogotá: CELAM, 2004.

Grégoire de Nysse. La vie de Moïse ou Traité de la perfection en matiére de vertu. Paris: Du Cerf, 1941.

Gutiérrez, G. Teología de la liberación. Salamanca: Sígueme, 1972.

Illanes, J. L. Historia y sentido. Estudios de Teología de la historia. Madrid: Rialp, 1997.

Laurent, B. Iniciación a la práctica de la teología. La práctica, acciones pastorales. Madrid: Cristiandad, 1983.

Libanio, J. B. y Murad, A. Introducción a la Teología. Perfiles, enfoques, tareas. Sao Paulo: Ediciones Loyola, 1996.

Lonergan, B. Método en teología. Salamanca: Sígueme, 2006.

Migne, J. P. Patrologiae Cursus Completus. Series Graeca. Vol. 46, Paris: 1863.

Moreno Martínez, J.L. La luz de los Padres: Temas Patrísticos de actualidad eclesial. Toledo: Instituto Teológico San Ildefonso, 2005.

Morín, E. Los siete saberes indispensables para la educación del futuro. Bogotá: Ediciones del Ministerio de Educación Nacional, 1996.

Moutsoulas, E. «Esencia y energías de Dios según San Gregorio de Nisa». Consultada en julio 18, 2013. http://www.ecclesia. com.br/Biblioteca/teologia/esencia_Y_energias_de_dios_segun_San_gregorio_de_nisa.html.

Patiño, J. U. Los Padres de la Iglesia. Una tradición como búsqueda teológica. Bogotá: San Pablo, 2005. 
Poupard, Paul. «Los Padres de la Iglesia: actualidad de una inculturación de la fe». En AA.VV. El diálogo fe-cultura en la antigüedad cristiana. Pamplona: EUNATE, 1996.

Rovira Belloso, J. M. Introducción a la teología. Madrid: BAC, 1996.

Standaert, N. «L'histoire d'un néologisme. Le terme 'inculturation' dans les documents romains». Nouvelle reveu théologique 110 (1988): 555-570.

Zañartu, S. «Revelación, tradición e inculturación: Pautas para un ensayo». Teología y vida 4, Vol. 44 (2003). Consultada en julio 24, 2013. http://www.scielo.cl/scielo.php?script=sci_ arttext\&pid =S $0049-34492003000400007 \& \operatorname{lng}$ $=$ es \&nrm $=$ iso $>$.ISSN 0049-3449.doi:10.4067/S004934492003000400007. 